\title{
INVESTIGATION ON WET-SNOW METAMORPHISM IN RESPECT OF LIQUID-WATER CONTENT
}

\author{
by \\ E. Brun \\ (Centre d'Études de la Neige, BP 44, 32404 Saint-Martin-d'Hères Cedex, France)
}

\section{ABSTRACT}

Up to the present time, quantitative investigations on wet-snow metamorphism have mostly been conducted on water-saturated snow, because of the difficulty in getting large enough wet-snow samples at a uniformly low liquid-water content. Using the dielectric properties of snow at a frequency in the range $20-100 \mathrm{kHz}$, a warming device has been developed which has enabled us to bring samples of $7 \times 10^{-3} \mathrm{~m}^{3}$ snow to any desired liquid-water content. A maximum value of $8 \%$ by volume was reached within $2 \mathrm{~h}$.

The warming device was used to reproduce natural wetness conditions in the laboratory in order to investigate wet snow metamorphism at low liquid-water content. Snow samples were brought to different liquid-water contents and held in that condition for about 2 weeks, during which grain-size was characterized using a picture-analysis system able to derive the mean radius of curvature of the cluster circumference. At any given liquid-water content value, the growth rate of the mean volume of the crystals building the clusters was constant, a pattern which has also been observed in water-saturated snow by previous investigators. This growth rate is well described by a power function of liquid-water content.

\section{INTRODUCTION}

Avalanche forecasting is based on knowledge of snow cover layering during the whole winter season in numerous locations of various orientations and elevations. At a given location snow-cover evolution depends only on the meteorological conditions which have prevailed since the beginning of the winter season. This is true for its energy balance as well as for its layering, since in each layer metamorphism depends on ambient temperature, liquid-water content, and the temperature gradient prevailing in the considered layer. These parameters depend directly on energy balance and also on mass balance.

Morphological knowledge of grain type and grain-size in a snow layer is of primary importance, because of the consequences for its mechanical properties and therefore on snow-pack stability. Moreover, radiative absorption models (Bohren and Barkstrom, 1972) confirmed by experimental results (Sergent and others, 1987) show that snow albedo in the solar spectrum is strongly dependent on grain-size. A realistic model for snowcover evolution should describe inner-layer metamorphism, which implies a quantitative knowledge of the laws of that metamorphism. Quantitative investigations have been conducted at high temperature gradients by Marbouty (1980) and at low temperature gradients by Brunot (unpublished) for dry snow.

For wet-snow metamorphism, theoretical bases were established by Colbeck (1973), who pointed out that graingrowth results from different melting-point temperatures being related to different radii of curvature at the ice interface; the larger grains grow while the smaller ones are melting. The growth rate increases with increased liquid-water content, since water mobility through the pores is thought to be the limiting factor for metamorphism at low liquid-water content. Until now, most quantitative investigations on wet-snow grain growth have been concerned with snow at saturated or high liquid-water content (Raymond and Tusima, 1979; Wakahama, 1968) because of the the difficulty in getting homogeneous snow samples at any given low or intermediate liquid-water content.

In its first section, this paper describes an original method of solving this problem using dielectric absorption of ice at a frequency in the range $20-100 \mathrm{kHz}$ in a uniform electric field. In its second section, the experimental method for investigating grain growth is described. Subsequently, experimental results are used to suggest a formula for grain growth as a function of liquid-water content.

\section{AN ORIGINAL DEVICE FOR UNIFORM} WARMING OF SNOW

Methods commonly in use to prepare wet snow samples cannot succeed in getting a homogeneous liquid-water content in a large snow sample because:

Ice melting at $0^{\circ} \mathrm{C}$ prevents the establishment of a temperature gradient, and liquid water cannot be formed in the inner parts of the sample by melting.

Regarding radiative absorption, a drawback is that it implies a decrease in size of heat source with depth.

Direct supply of liquid water causes percolation that is not necessarily homogeneous but may be preferentially located in selected channels.

The dielectric properties of ice enable heat to be dissipated through the whole volume of snow exposed to an electric field which is oscillating at an appropriate frequency. If the electric field has a uniform spatial distribution, heat absorption by the ice phase is also uniform and the absorbed energy depends on the imaginary part $\varepsilon^{\prime \prime}$ of permittivity. The dielectric behaviour of snow is well described by mixing theory (Polder and Van Santen, $1946)$, and the relaxation frequency of dry snow lies between 10 and $100 \mathrm{kHz}$, according to the work of Kuroiwa (1962). In this frequency range water is far less absorbent than ice, so that energy dissipation by wet snow is little affected by the presence of liquid water so long as the liquid phase remains discontinuous. This allows a maximum liquid-water content in this type of snow of about $14 \%$ of the pore volume (Colbeck, 1973). On the basis of this figure an original device has been developed for the uniform warming of snow as shown in Figure 1. Numerous experiments on snow warming have been conducted, and theoretical predictions of melt rate and of a uniform distribution of liquid water in snow samples were well confirmed by experimental results. The temperature field of warmed dry snow samples appears spatially uniform, except near the boundary, due to conductive heat losses in the Plexiglass container. If the warming process is continued beyond the melting point, liquid-water content is increased 


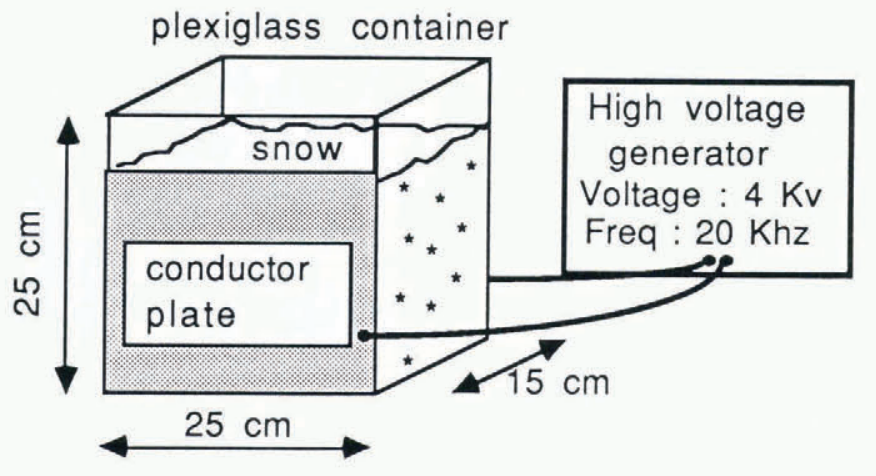

Fig. 1. Snow-warming device.

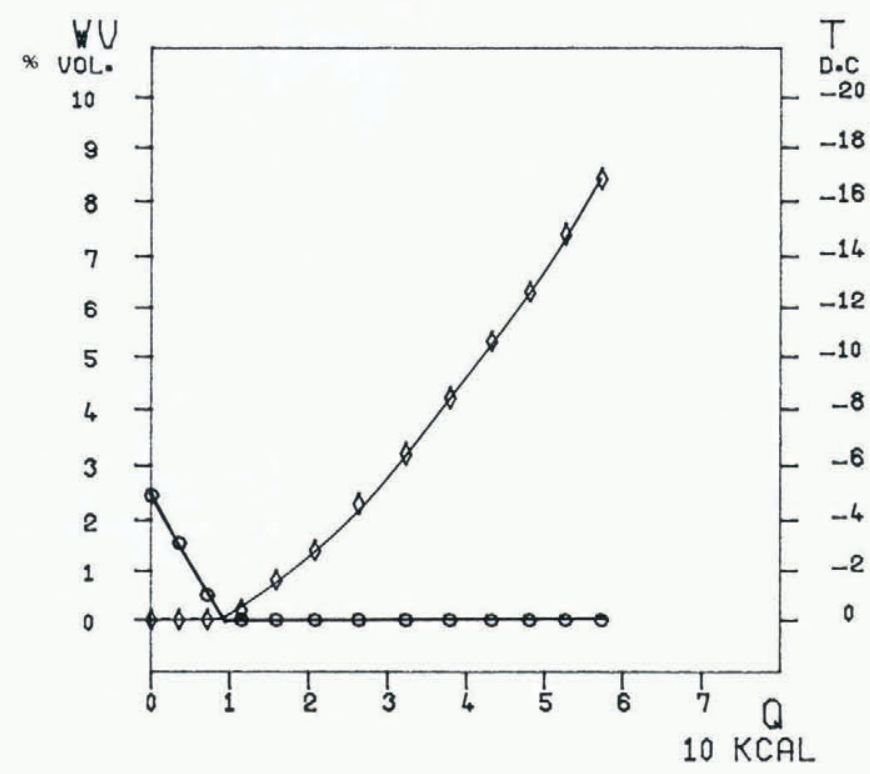

Fig. 2. Snow temperatures and liquid-water content plotted against energy supplied by warming process during a $2 \mathrm{~h}$ period.

uniformly at a constant rate, as shown in Figure 2 . Uniform distribution of liquid-water content is effectively maintained in snow samples until the irreducible water content is reached and percolation begins.

2. EXPERIMENTAL INVESTIGATION OF GRAINGROWTH RATE IN RELATION TO LIQUID-WATER CONTENT

\section{Experimental process}

Fresh dry snow is collected in the field and brought into the cold laboratory. After sifting, every $7 \times 10^{-3} \mathrm{~m}^{3}$ snow sample of is put in a Plexiglass container and held at a uniform temperature of about $-5^{\circ} \mathrm{C}$. The snow sample is then exposed to the warming process described above; its temperature reaches $0^{\circ} \mathrm{C}$ and its liquid-water content rises homogeneously throughout the sample. The total amount of energy supplied differs from one sample to another due mainly to differences in snow density. The rate of warming also varies between samples but within a smaller range. Heat dissipation rate is deduced from the temperature increase recorded within the first ten minutes of warming. The duration of warming needed to get the snow to the desired liquid-water content is then calculated. Following which, liquid-water content is measured using a dielectric probe at a frequency about $13 \mathrm{MHz}$.

The sample is then put into a box surrounded by an ice-water bath, to avoid any further melting or freezing, for about 2 weeks. The bath is insulated (Fig. 3) to prevent heat transfer between the wet snow and the external environment. Ice and water masses remain unchanged during the experiment yet nevertheless

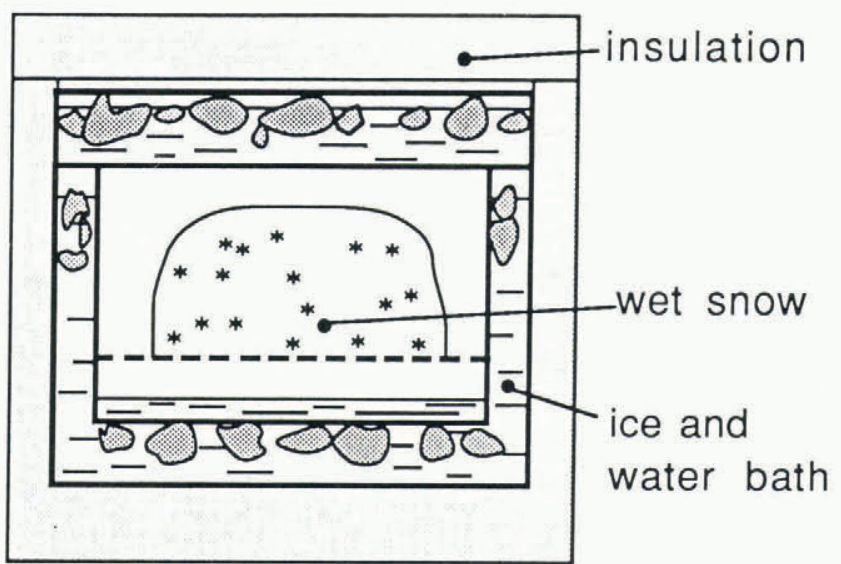

Fig. 3. Wet-snow storage device.

liquid-water content, expressed as a bulk ratio, remains unchanged only when percolation does not occur through the snow. This happens when snow liquid-water content is higher than the irreducible saturation, a characteristic which depends on snow type. Denoth and others (1979) have suggested experimental values of around $5 \%$ of pore volume, corresponding to a liquid-water content by around 9\% mass for snow samples with a density in the order of 0.35 , which is also typical for our samples a few hours after the initial warming process. If percolation occurs, a watersaturated layer appears at the bottom of the snow sample and some water may run off beneath the sample until its liquid-water content in its central region reaches irreducible value.

In these experiments it was convenient to consider liquid-water content as a percentage of mass rather than volume because density increased with time, involving a changing volume even when the amount of water remained unchanged.

\section{Snow characterization}

Snow samples were initially taken from fresh or partly branched snow, and wet metamorphism involved first a quick change in crystal shape until the dendritic parts had disappeared, and then the rounded particles grew with time. The first step of the metamorphism is difficult to quantify, since it causes change of shape rather than of size; in fact, it changes the specific surface area. Snow morphology was characterized by taking a sub-sample from the central region of the sample at regular intervals. This sub-sample was disaggregated in methyl heptane (iso-octane) at $-5^{\circ} \mathrm{C}$, in order both to freeze the liquid water and to avoid the development of bonds between the grains. In the experiments conducted in water-saturated snow by Raymond and Tusima, and by Wakahama, the crystals formed were isolated and quasi-spherical, so that there was no ambiguity in assigning them a size. In our work, the snow formed clusters in which quasi-spherical crystals were bound

\section{TABLE I. SUMMARY OF EXPERIMENTS}

$\begin{array}{crrrrr}\begin{array}{c}\text { Experi- } \\ \text { ment } \\ \text { number }\end{array} & \begin{array}{r}\text { Liquid } \\ \text { water }\end{array} & \begin{array}{l}\text { Dura- } \\ \text { tion }\end{array} & \begin{array}{c}\text { Initial } \\ \text { density }\end{array} & \begin{array}{c}\text { Occurence } \\ \text { of } \\ \text { percolation }\end{array} & \begin{array}{c}\text { Growth } \\ \text { rate }\end{array} \\ & & & & & \end{array}$

(\% mass) (h)

$v\left(\mathrm{~mm}^{3} \mathrm{~s}^{-1}\right)$

s


$L W C=0 \%$

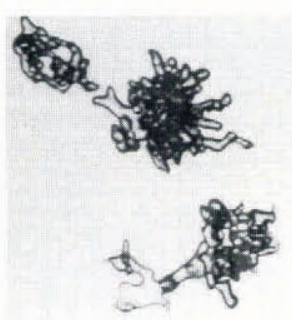

2 hours

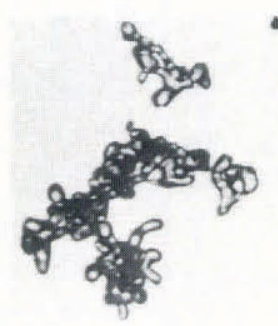

0 hour

LWC $=3.7 \%$

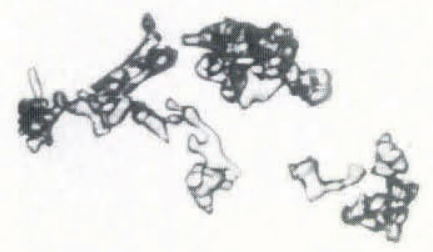

0 hour

$L W C=7 \%$

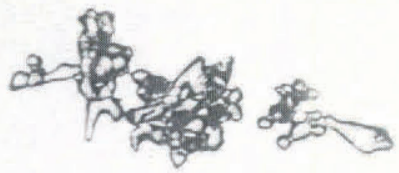

0 hour

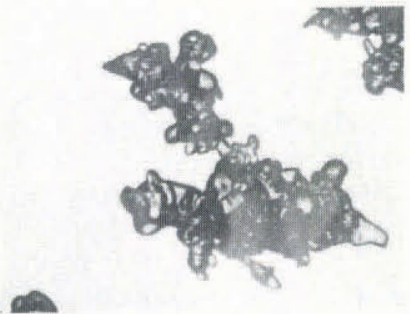

0 hour

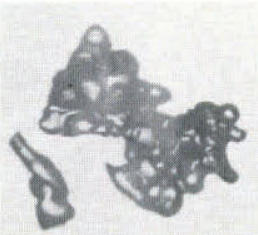

n

0 hour

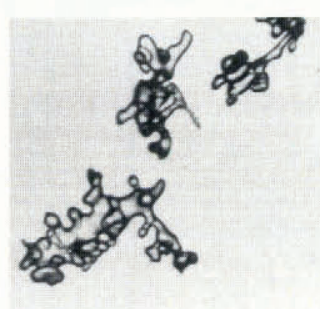

118 hours

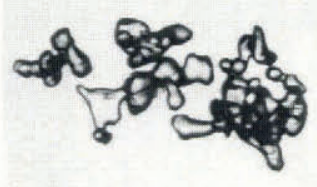

101 hours

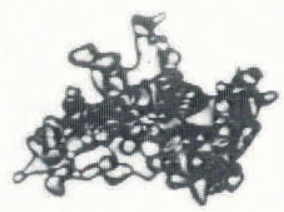

97 hours

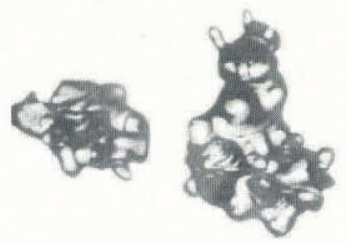

124 hours

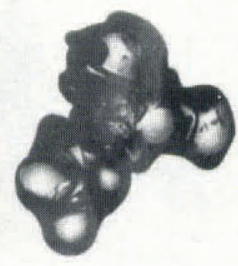

112 hours

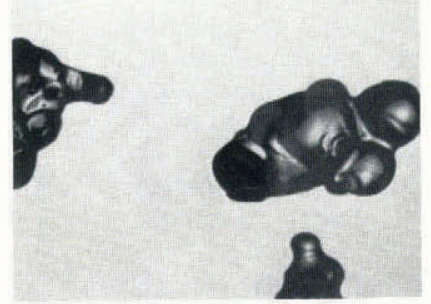

138 hours

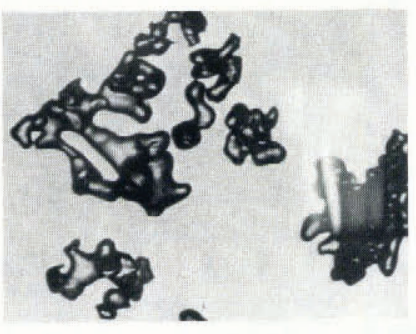

239 hours

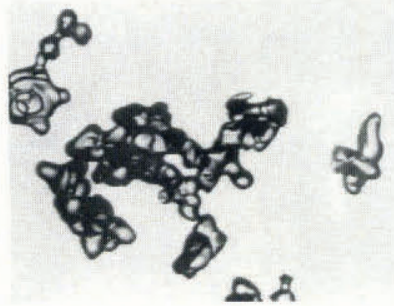

223 hours

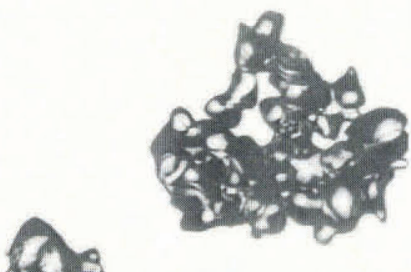

219 hours

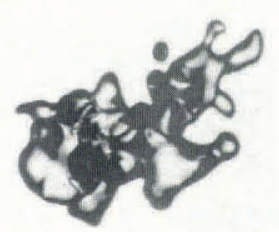

241 hours

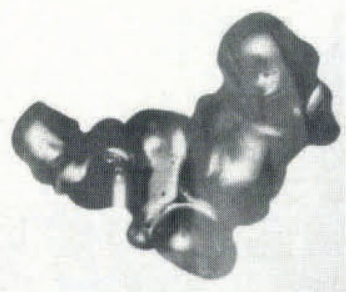

189 hours

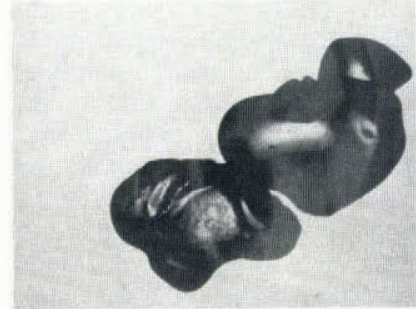

217 hours

Fig. 4. Typical shape of snow grains during each experiment. Beneath each picture time elapsed since end of warming process. Liquid-water content expressed as per cent of mass. 

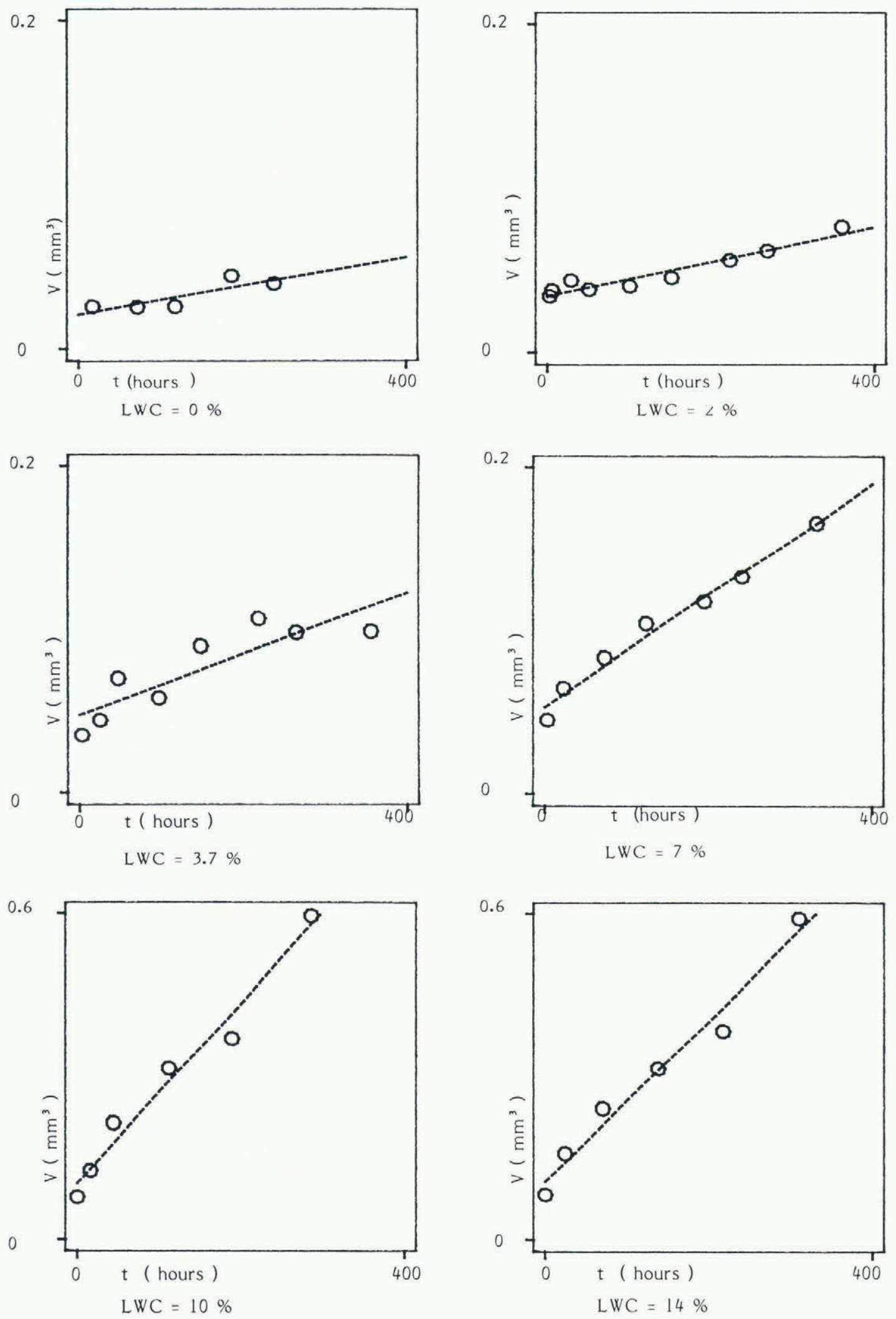

Fig. 5. Equivalent volume, $v$, plotted against time for each experiment. Liquid-water content expressed as per cent of mass.

together either by the original bonds in the wet snow or by bonds built after extraction from the sample when liquid water was frozen in the cold methyl heptane.

Grain-size is defined as the size of the crystals which can be seen along the circumference of the clusters. Obviously, this size varies from one crystal to another so that a large number of them must be observed in order to derive the mean grain-size of the sample. A picture-analysis system has been developed which computes the mean convex radius of curvature from about 20 randomly chosen clusters, corresponding to a sample size of about 100 different crystals, thus ensuring a significant grain-size distribution.

\section{EXPERIMENTAL RESULTS}

Six groups of experiments were conducted on snow samples with different liquid-water contents, as described in Table I. 
Initial density differs from that recorded during the experiment because of a large density increase during the warming process, when the sample shrinks throughout early wet metamorphism particularly in the newest snow. In experiment No. 1, snow was warmed to $-0.3^{\circ} \mathrm{C}$ after which a temperature of $0^{\circ} \mathrm{C}$ was reached by conduction in the box surrounded by the ice-water bath without change in liquid-water content. Figure 4 shows the typical shapes of snow grains during various experiments. The elapsed time since the end of warming is written on every picture. Initial metamorphism that occurs during the warming process involves a rapid change in grain shape as the dendritic structure disappear; the higher the liquid-water content of the original sample the quicker the change.

Focusing on the growth of the rounded grains, we noted that Raymond and Tusima have observed in saturated snow that the cumulative distribution of particle diameters had the same pattern with increasing time and could be shifted from the original one by fitting only the median diameter, and that the same was true for volume distribution. Such a result would explain the linear increase in mean volume with time which they observed in all their experiments. In our experiments, at low liquid-water content the grains were not spherical, but the crystals bonded together to build clusters showed a cumulative sizedistribution qualitatively similar to that described by Raymond and Tusima. Our picture-analysis system was not able to compute the radius of each individual crystal but gave the mean radius of curvature along the convex parts of the cluster. For each experiment, the volume of the equivalent sphere deduced from the mean convex radius of the sample, was plotted against time (Fig. 5). Since the mean radius is well described by our system, this equivalent volume correlates well with the mean volume of the crystals building each clusters.

The results represented in Figure 5 show a linear increase in mean volume in each experiment, a similar trend to that observed in saturated snow. Growth rate increased as liquid-water content increased up to the irreducible water content and beyond this value percolation occured (experiments 5 and 6 ) and growth rate no longer increased. Wet snow metamorphism at low liquid-water contents may thus be described by the growth rate of the mean volume of the rounded grains as a linear function of time; and expressed as

$$
v(t)=v_{0}+v^{\prime *} t
$$

where $v_{0}=$ initial sample volume, and $t=$ time

Figure 6 shows that the growth rate $v^{\prime}$, in our experiments, may be expressed as the following function of liquid-water content $(L)$ :

$$
v^{\prime}=v_{0}^{\prime}+v_{1}^{\prime *} L^{3} \text {. }
$$

If volume is expressed in $\mathrm{mm}^{3}$, time in $\mathrm{s}$ and $L$ in per

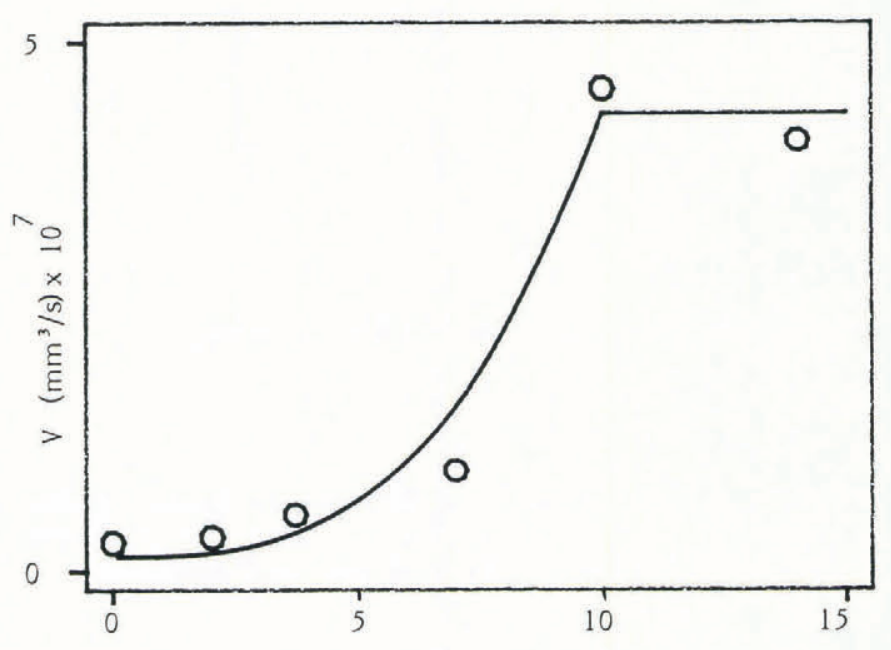

LWC ( \% per mass )

Fig. 6. Growth rate plotted against (liquid-water content) ${ }^{3}$, expressed as per cent of mass. cent of total mass (with a maximum value of 9 to 10), then:

$$
v_{0}^{\prime}=1.28 \times 10^{-8} \mathrm{~mm}^{3} \mathrm{~s}^{-1} ; v_{1}^{\prime}=4.22 \times 10^{-10} \mathrm{~mm}^{3} \mathrm{~s}^{-1} .
$$

Assuming that wet-snow metamorphism is limited at low wetness by mobility of liquid water from the melting parts to the freezing parts of the sample, the power function for the growth rate may be an illustration of the effect of the liquid-water content on the probability of building sufficiently long enough continuous paths over the ice surfaces in contact with the liquid phase. The coefficient, $v^{\prime}$, observed by Raymond and Tusima in saturated snow is about three times greater than our maximum value, which is also the case for the irreducible free water content. These results are therefore in agreement, since the latter case corresponds with the beginning of the pendular regime of percolation where, as described by Colbeck (1973), the liquid phase remains discontinuous thus limiting the opportunity for water to move easily across the whole ice surface. In saturated snow, liquid water is present over the whole surface and the limiting factor in percolation is the heat flow from the freezing zone to the melting zone.

The effects of impurities, which have been discussed by Raymond and Tusima, have not been taken into account in our calculations, since our snow samples were taken from an alpine area where the concentrations of contaminants are normally lower than the values necessary to cause decrease in crystal-growth rate.

\section{CONCLUSION}

An original device has been developed by our research group which can provide snow samples with a given liquid-water content uniformly distributed throughout the whole sample volume. This device has already been used to reproduce natural wetness conditions in the laboratory in order to facilitate the investigation of wet-snow metamorphism in snow samples with low liquid-water content. As with saturated snow the mean volume of the crystals increases at a constant rate, and this rate may be expressed as a power function of the liquid-water content. Such a formula may be integrated into snow-cover energybalance models to take into account the effects of grain-size on solar absorption and on permeability, and therefore to forecast run-off. Eventually, the snow-warming device we have developed may prove useful in investigations of topics such as the mechanical properties, water movements, and liquid-water measurements, for wet snow or ice.

\section{REFERENCES}

Bohren, C.F. and B. R. Barkstrom. 1974. Theory of the optical properties of snow. J. Geophys. Res., 79(30), 4527-4535.

Colbeck, S.C. 1973. Theory of metamorphism of wet snow. CRREL Res. Rep. 313.

Denoth, A., W. Seidenbusch, M. Blumthaler, P. Kirchlechner, W. Ambach, and S.C. Colbeck. 1979. Study of water drainage from columns of snow. CRREL Rep. 79-1.

Kuroiwa, D. 1962. Electrical properties of snow. CRREL CRSE Part 2. Section 13, 63-73.

Marbouty, D. 1980. An experimental study of temperaturegradient metamorphism. J. Glaciol., 26(94), 303-312.

Polder, D. and J.H. van Santen. 1946. The effective permeability of mixtures of solids. Physica, 12(5), $257-271$

Raymond, C.F. and K. Tusima. 1979. Grain coarsening of water-saturated snow. J. Glaciol., 22(86), 83-105.

Sergent, C., P. Chevrand, J. Lafeuille, and D. Marbouty. 1987. Caractérisation optique de différents types de neige. Extinction de la lumière dans la neige. J. Phys. (Paris), 48, Colloq. C1, 361-367. (Supplèment au 3.)

Wakahama, G. 1968. The metamorphism of wet snow. International Association of Scientific Hydrology Publication 79 (General Assembly of Bern 1967 - Snow and Ice), 370-379. 